\title{
A link between promoter polymorphisms of the transforming growth factor $\beta 1$ (TGFB1) and TGF- $\beta 1$ receptor II (TGFBR2) genes and relapsing-remitting multiple sclerosis
}

\author{
Antonia Grigorova ${ }^{1}$, Anastasiya Trenova², Spaska Stanilova ${ }^{1}$ \\ ${ }^{1}$ Department of Molecular Biology, Immunology, and Medical Genetics, Medical Faculty Trakia University, Stara Zagora, Bulgaria, \\ ${ }^{2}$ Department of Neurology, Faculty of Medicine, Medical University of Plovdiv, Bulgaria
}

\begin{abstract}
Introduction: Multiple sclerosis (MS) is a chronic progressive autoimmune disease characterised by nerve demyelination, mediated by myelin-specific Th1 autoreactive cells. Transforming growth factor $\beta 1$ (TGF- $\beta 1$ ) is a regulatory cytokine involved in MS aetiology by maintaining CD4+ cell differentiation and preventing autoimmune responses. Because of the important role of the TGF- $\beta 1$ signalling pathway in MS aetiopathogenesis, we aimed to investigate the association of two DNA polymorphisms: TGFB1C[-509]T and TGFBR2G[-875]A and their combined genotypes with the risk of MS development in a cohort of Bulgarian patients. The effect of the two promoter polymorphisms on the disease onset was also assessed.

Material and methods: In the study, a cohort of 183 patients with relapsing-remitting multiple sclerosis (RRMS) and 307 sex- and age-matched healthy subjects were recruited. Genotyping of the TGFB1C[-509]T (rs1800469) and TGFBR2G[-875]A (rs3087465) polymorphisms was performed by PCR-RFLP and PIRA-PCR approaches.

Results: Frequencies of the TGFB1T[-509]T genotype and TGFB1[-509] ${ }^{\star}$ T-allele were lower in RRMS men than in control healthy men (15.7\% vs. $26.9 \%, 37.3 \%$ vs. 50.7\%, respectively). Among males, the TGFB1T[-509]T genotype was related to a significantly reduced risk of RRMS $(O R=0.360,95 \% \mathrm{Cl}: 0.126-1.028, p=0.05)$ in comparison to the TGF$B 1 C[-509] C$ genotype. Also, TGFB1[-509] ${ }^{\star}$-allele was more common in men with RRMS than in healthy men relative to the TGFB 1[-509] ${ }^{*} \mathrm{C}$-allele and was associated with a statistically significant protective effect $(O R=0.576,95 \% \mathrm{Cl}$ : 0.341-0.974, $p=0.039$ ). The combination of TGFB1T[-509]T/TGFB1T[-509]C and TGFBR2G[-875]A genotypes among men was associated with a significant protective effect compared to the wild-type homozygous TGFB1C[-509]C and TGFBR2G[-875]G genotypes (OR $=0.268,95 \% \mathrm{Cl}$ : 0.088-0.818, $p=0.018)$. No significant association between rs 1800469 and rs 3087465 was observed among females with and without (controls) RRMS.

Conclusions: In summary, we suggest that in males, a higher TGF- $\beta 1$ level determined by TGFB1T[-509]T genotype in combination with the TGFBR2G[-875]A genotype might be a protective factor against RRMS development.
\end{abstract}

Key words: multiple sclerosis (MS), cytokine, TGFB1 gene, TGFBR2 gene, SNP.

Communicating author

Antonia Grigorova, Department of Molecular Biology, Immunology, and Medical Genetics, Medical Faculty, Trakia University,

11 Armeiska St., 6000 Stara Zagora, Bulgaria, e-mail: antoniagrigorova78@gmail.com 


\section{Introduction}

Multiple sclerosis (MS) is a chronic autoimmune disease characterised by demyelination and neurodegeneration in the central nervous system (CNS), mainly affecting women. Immune abnormalities include both the presence of activated autoreactive $T$ cells and the autoantibodies against myelin, which suggest that defects in immune system regulation contribute to the pathogenesis of the disease $[2,12]$. Relapsing-remitting MS (RRMS) is described by unpredictable relapses followed by a period of improvement or stable clinical condition (remission), lasting at least a month [1]. Underlining events include disturbance in the tolerance to self-antigens, particularly myelin basic protein, and triggering of the severe autoimmune process, which progresses when left untreated, leading to nerve degeneration. It is well-known that thymus-derived natural $T$ regulatory (Tregs) cells (CD4+CD25+FoxP3+) are a major player in maintaining self-tolerance and preventing autoimmune responses. Experiments with animal models clearly show that the depletion of Tregs causes induction of severe autoimmune conditions of the CNS [21]. Several studies provide evidence that in MS, the suppressive role of Tregs is diminished due to reduced suppressive capacity, and diminished number or restricted T-cell receptor (TCR) repertoire of CD4+CD25+FoxP3+ cells [8,14,34]. The molecular mechanism of Tregs negative control on immune response includes the production of the transforming growth factor $\beta 1$ (TGF- $\beta 1$ ), activation of intracellular TGF- $\beta 1$ signalling pathway, and expression of Foxp3 transcription factor [19]. Loss of TGF- $\beta 1$ in knockout mice resulted in the development of multifocal inflammatory disease [32]. A dominant-negative TGF- $\beta$ receptor type II mouse model also developed autoimmune disease [4].

Alterations of TGF- $\beta 1$ expression, the immunosuppressive cytokine, have been reported in MS. But it remains not fully defined whether the reduced level of TGF- $\beta$ or changed TGF- $\beta$ signal transduction pathway contributes to the pathogenesis of the disease $[7,34]$. Therefore, TGF- $\beta 1$ is one of the most extensively studied cytokines, regarding the immunopathogenesis of RRMS [16]. TGF- $\beta 1$ is a cytokine with regulatory activities that orchestrate the differentiation of both Tregs and T helper 17 (Th17) cells in a concentration-dependent manner - low doses induce Th17 cell differentiation, while high doses inhibit Th17 cell development and promote Tregs [25]. In MS TGF- $\beta 1$ plays a negative role in the differentiation of encephalitogenic Th17 cells and diminishes the encephalitogenic capacity of myelin-specific Th1 cells by inducing robust production of interleukin 10 (IL-10) in an SMAD4-dependent manner. The SMAD4 (SMAD family member 4 gene) protein is a central mediator of the TGF- $\beta$ canonical signalling pathway. This protein forms homomeric or heteromeric complexes with other activated Smad proteins, which then accumulate in the nucleus and serve as the transcription factors that regulate the expression of target genes leading to enhancement of Th1 and Th17 response $[10,17,36]$.

The effect of TGF- $\beta 1$ on target cells is mediated by two receptors: TGFBR1 and TGFBR2. TGF- 1 binds to the TGFBR2, which recruits a type I receptor dimer to create a hetero-tetrameric complex that induces SMAD-dependent or SMAD-independent intracellular signalling pathway [31]. TGF- $\beta$ signalling is altered in MS, and the modulation of this intracellular pathway may represent a potential target for therapy $[23,24]$. The inability of Tregs in patients with MS to suppress autoimmunity could be attributed to decreased TGFBR2 expression and/or disturbance in the intracellular transducing pathway. In a recent study, it was shown that TGFBR2 expression was reduced in CD4+ T-cells of RRMS patients [22]. In view of the importance of the TGF- $\beta 1$ signalling pathway in the aetiology of MS, our understanding of how genetic polymorphisms located in the TGF- $\beta 1$ gene and in genes for TGF- $\beta 1$ receptors influence MS development seems to be important.

The TGFB1 gene is located on chromosome 19 in the $19 q 13.2$ region, and several polymorphisms have been identified in the gene, including a promoter polymorphism at -509 position (rs1800469), which is due to a C-to-T transition (TGFB1C[-509]T) and strongly affects the level of TGF- $\beta 1$ expression [30]. The TGFBR2 gene located on chromosome 1 in the $1 q 41$ region and the polymorphic variant in the promoter region of TGFBR2 (rs3087465), causing a G-to-A transition, was reported by Seijo et al. and was not explored previously as a genetic risk factor for RRMS [28].

Because of the important role of TGF- $\beta 1$ signalling pathway in the development of MS, we aimed to investigate the association between two promoter polymorphisms in the two different genes: TGFB1C[-509]T and TGFBR2G[-875]A and/or a combina- 
tion of the observed genotypes with a risk of MS in a cohort of Bulgarian patients using a case-control gene-association study approach. We also calculated the combined effect of the two promoter polymorphisms on the onset of the disease.

\section{Material and methods \\ Patients and controls}

This study included a group of 183 patients, consisting of 132 women and 51 men with RRMS. The disease type was defined as relapsing-remitting, according to McDonald's criteria [26]. Patients' disability was estimated by using the Expanded Disability Status Scale (EDSS) [15]. All patients were between 18 and 60 years of age and were in a remission stage of the disease (defined as a period of improvement or stable clinical condition for at least 3 months). With regard to disease-modifying therapy, $80.3 \%$ of the patients were treated with interferon $\beta$ (IFN- $\beta$ ), $14.2 \%$ were treated with glatiramer acetate for at least six months, and $5.5 \%$ were without treatment. All patients were with an EDSS score in the range 1.0 to 4.0. According to the onset of the disease, the group of RRMS patients was separated into two subgroups: early-onset - under 30 years (51.9\%) and late-onset - above 30 years (48.1\%). All patients were recruited from the Department of Neurology, Medical University-Plovdiv. The clinical characteristics of the RRMS patients are presented in Table I. The control group consisted of 307 healthy volunteers, matched with patients by age and gender. The healthy controls included 240 females and 67 males, with a mean $( \pm S D)$ age of $42.28 \pm 13.17$ years.

All cases and controls were Caucasians. The involvement of participants in the study was certified by written informed consent, according to the ethical guidelines of the Helsinki Declaration.

\section{Genotyping of TGFB1C[-509]T and TGFBR2G[-875]A promoter polymorphisms}

Genomic DNA from peripheral blood samples was extracted using Gene Matrix Purification Kit (EURx, Poland) following the manufacturer's instructions.

Genotyping of the TGFB1C[-509]T (rs1800469) was performed by polymerase chain reaction-restriction fragment length polymorphism (PCR-RFLP) assay, as described in detail previously [33]. The set of primers used for amplification of 153bp fragment were as follows: forward primer 5'-CAGTAAATGTATGGGGTCGCAG-3' and reverse primer 5'-GGTGTCAGTGGGAGGAGGG-3'. The conditions of the PCR reaction were initial incubation of samples for $3 \mathrm{~min}$ at $94^{\circ} \mathrm{C}$, and after that 30 cycles as follows: denaturation for $45 \mathrm{~s}$ at $94^{\circ} \mathrm{C}$, annealing for $45 \mathrm{~s}$ at $63.3^{\circ} \mathrm{C}$, and extension for $45 \mathrm{~s}$ at $72^{\circ} \mathrm{C}$; and final extension for $7 \mathrm{~min}$ at $72^{\circ} \mathrm{C}$. The amplicons were digested with $10 \cup$ Eco81l enzyme (Thermo Fisher Scientific) per reaction overnight at $37^{\circ} \mathrm{C}$. The final products were electrophoresed on $3.5 \%$ agarose gel and visualised directly with ethidium bromide staining. Alleles were represented by $115 \mathrm{bp}$ and 38bp DNA fragments corresponding to the TGFB1 $[-509]^{*} \mathrm{C}$ allele and a $153 \mathrm{bp}$ DNA fragment corresponding to the TGFB1[-509] ${ }^{*} T$ allele.

The genotyping of the TGFBR2G[-875]A (rs3087465) polymorphism was performed by primerintroduced restriction analyses (PIRA-PCR) assay [13]. The primer sequences were the following: forward primer 5'-GCAAGAAAGGAAATTTGAAAGTTTGT-3' and reverse primer 5'-TCACCTGAATGCTTGTGCTTTT-3'. The PCR amplification was performed under the

Table I. Clinical characteristics of relapsing-remitting multiple sclerosis (RRMS) patients

\begin{tabular}{|c|c|}
\hline Characteristics & $\begin{array}{c}\text { RRMS patients } \\
N=183\end{array}$ \\
\hline Age (mean $\pm S D$ ) in years & $40.50 \pm 9.01$ \\
\hline \multicolumn{2}{|l|}{ Gender, n (\%) } \\
\hline Female & $132(72.1 \%)$ \\
\hline Male & $51(27.9 \%)$ \\
\hline \multicolumn{2}{|l|}{ DMT, $n(\%)$} \\
\hline Interferon $\beta$ & $147(80.3 \%)$ \\
\hline Glatiramer acetate & $26(14.2 \%)$ \\
\hline No treatment & $10(5.5 \%)$ \\
\hline $\begin{array}{l}\text { Mean duration of DMT } \\
\text { (mean } \pm \text { SD) in months }\end{array}$ & $57.45 \pm 37.19$ \\
\hline $\begin{array}{l}\text { Age of onset of the disease } \\
(\text { mean } \pm S D) \text { in years }\end{array}$ & $29.86 \pm 8.28$ \\
\hline $\begin{array}{l}\text { Onset of RRMS }<30 \text { years, } n(\%) \\
(\text { mean } \pm \text { SD) }\end{array}$ & $\begin{array}{l}95(51.9 \%) \\
23.21 \pm 3.83\end{array}$ \\
\hline $\begin{array}{l}\text { Onset of RRMS } \geq 30 \text { years } \\
\text { (mean } \pm \text { SD) }\end{array}$ & $\begin{array}{l}88(48.1 \%) \\
37.05 \pm 5.19\end{array}$ \\
\hline $\begin{array}{l}\text { Duration of the disease } \\
(\text { mean } \pm S D) \text { in years }\end{array}$ & $10.62 \pm 6.13$ \\
\hline EDSS $($ mean \pm SD) & $2.03 \pm 0.90$ \\
\hline
\end{tabular}

RRMS - relapsing-remitting multiple sclerosis, SD - standard deviation, $D M T$ - disease-modifying treatment, EDSS - Expanded Disability Status Scale 
following conditions: initial denaturation at $94^{\circ} \mathrm{C}$ for $5 \mathrm{~min}$, followed by 30 cycles of $45 \mathrm{~s}$ at $94^{\circ} \mathrm{C}$, for $45 \mathrm{~s}$ at $57^{\circ} \mathrm{C}$ and $45 \mathrm{~s}$ at $72^{\circ} \mathrm{C}$, and completed with final extension cycle for $7 \mathrm{~min}$ at $72^{\circ} \mathrm{C}$. The $124 \mathrm{bp} \mathrm{PCR}$ products were digested with $\mathrm{Rsal}(10 \mathrm{U} / \mu \mathrm{l})$ restriction enzyme at $37^{\circ} \mathrm{C}$ overnight. The final products were electrophoresed on 3.5\% agarose gel and visualised directly with ethidium bromide staining. The TGFBR2 $[-875]^{\star} A$ allele produced two DNA fragments with lengths of $99 \mathrm{bp}$ and $25 \mathrm{bp}$, while TGFBR2[-875]* $\mathrm{G}$ allele resulted in a fragment of $124 \mathrm{bp}$.

All PCR reactions were performed in the GeneAmp PCR System 9700 (Applied Biosystems). The reagents for $P C R$ and primers were provided by Thermo Fisher Scientific (USA) and Metabion $\mathrm{GmbH}$ (Germany).

\section{Statistical analysis}

Statistical data processing was performed using the Statistica software package (StatSoft Inc., USA) version 12.0. The differences in the distribution of genotype and allele frequencies between patients and controls were analysed using the $\chi^{2}$ test. The Fisher exact test and Yates' corrected $p$-value $\left(p_{c}\right)$ were used when the observed frequencies comprised a smaller group. The association between analysed genotypes of the TGFB1 and TGFBR 2 genes and risk of RRMS were estimated by calculating the odds ratios (ODs) and 95\% confidence intervals (95\% Cl) using the StatPages.net website (http://statpages. org/index.html). The Hardy-Weinberg equilibrium was tested by comparing the observed genotype frequencies to the expected frequencies for cases and controls by the $\chi^{2}$ test. All data were regarded as significant at $p \leq 0.05$.

\section{Results}

\section{Association of TGFB1C[-509]T and TGFBR2G[-875]A polymorphisms with RRMS susceptibility}

The different genotype and allele frequencies of the TGFB1C[-509]T and TGFBR2G[-875]A promoter polymorphisms in the cases and controls are presented in Table II. The observed genotype distribution for TGFB1C[-509]T and TGFBR2G[-875]A (rs1800469 and rs3087465) showed no deviation from HardyWeinberg equilibrium in the patients with RRMS $\left(\chi^{2}=0.026, p=0.987, \chi^{2}=2.228, p=0.328\right)$ and controls $\left(\chi^{2}=0.977, p=0.613, \chi^{2}=0.122, p=0.940\right.$, respectively). The differences between cases and controls, in the distribution of the genotypes of both studied polymorphisms (rs1800469 and rs3087465), were non-significant (rs1800469: $\chi^{2}=2.302, p=$ 0.316 , rs3087465: $\chi^{2}=2.342, p=0.31$ ). However, the analyses of data after stratification by sex showed that the frequency of TGFB1T[-509]T genotype and TGFB1[-509] ${ }^{*}$-allele was decreased in RRMS men compared to healthy men ( $15.7 \%$ vs. $26.9 \%, 37.3 \%$ vs. $50.7 \%$, respectively). Moreover, the homozygous TGFB1T[-509]T genotype was related to a significantly reduced risk of RRMS (OR $=0.360,95 \% \mathrm{Cl}$ : $0.126-1.028, p=0.05)$ referred to the TGFB1C[-509]C genotype among men. Also, TGFB1[-509]*T allele was more common in men with RRMS than among healthy men and was associated with a statistically significant protective effect $(\mathrm{OR}=0.576,95 \% \mathrm{Cl}$ : $0.341-0.974, p=0.039)$. The observed distribution of genotypes of both polymorphisms was similar among groups of RRMS and healthy women.

\section{The combined effect of the rs 1800469 and rs3087465 polymorphisms on RRMS susceptibility}

Further, we studied the effect of TGFB1C[-509]T and TGFBR2G[-875]A genotype combination for RRMS susceptibility in our groups. The results presented in Table III indicate that the combination of the TGFB1T[-509]T with TGFBR2G[-875]A genotypes as well as TGFB1T[-509]T and TGFBR2G[-875]A/ TGFBR2A[-875]A are associated with significantly reduced risk of RRMS compared to TGFB1C[-509]C and TGFBR2G[-875]G genotypes ( $\mathrm{OR}=0.357,95 \% \mathrm{Cl}$ : $0.136-0.938, p=0.032$; OR $=0.411,95 \% \mathrm{Cl}: 0.173$ $0.976, p=0.040$ ). Similarly, when we combined the TGFB1T[-509]C/TGFB1T[-509]T and TGFBR2G[-875]A genotypes among men, compared to those carrying both wild-type homozygotes TGFB1C[-509]C and TGFBR2G[-875]G genotypes, the significance of protective effect increased $(\mathrm{OR}=0.268,95 \% \mathrm{Cl}$ : $0.088-0.818, p=0.018$ ). No significant association was observed between rs 1800469 and rs3087465 among women with RRMS and controls.

\section{Association of TGFB1C[-509]T and TGFBR2G[-875]A polymorphisms with the onset of RRMS disease}

As regards to the importance of TGFB1C[-509]T and TGFBR2G[-875]A promoter polymorphisms for 
Table II. Genotype and allele distribution of -509C/T TGFB1 and -875G/A TGFBR2 polymorphisms in relapsing-remitting multiple sclerosis (RRMS) patients and healthy controls

\begin{tabular}{|c|c|c|c|c|}
\hline Genotype & RRMS, $n(\%)$ & Controls, $n(\%)$ & OR $(95 \% \mathrm{Cl})$ & $P$-value \\
\hline \multicolumn{5}{|c|}{ TGFB1 -509C/T (rs1800469) } \\
\hline Total N & 183 & 307 & & \\
\hline $\mathrm{CC}$ & $70(38.3)$ & $104(33.9)$ & ref. & \\
\hline $\mathrm{CT}$ & $86(47)$ & $142(46.2)$ & $0.900(0.601-1.348)$ & 0.609 \\
\hline $\mathrm{TT}$ & $27(14.7)$ & $61(19.9)$ & $0.658(0.381-1.134)$ & 0.131 \\
\hline $\mathrm{CT} / \mathrm{TT}$ & $113(61.7)$ & $203(66.1)$ & $0.827(0.565-1.210)$ & 0.328 \\
\hline C allele & $226(61.7)$ & $350(57)$ & ref. & \\
\hline T allele & $140(38.3)$ & $264(43)$ & $0.821(0.630-1.070)$ & 0.144 \\
\hline Female $n$ & 132 & 240 & & \\
\hline $\mathrm{CC}$ & $49(37.1)$ & $87(36.3)$ & ref. & \\
\hline CT & $64(48.5)$ & $110(45.8)$ & $1.033(0.648-1.647)$ & 0.891 \\
\hline TT & $19(14.4)$ & $43(17.9)$ & $0.785(0.412-1.493)$ & 0.459 \\
\hline $\mathrm{CT} / \mathrm{TT}$ & $83(62.9)$ & $153(63.7)$ & $0.963(0.620-1.496)$ & 0.867 \\
\hline C allele & $162(61.4)$ & $284(59.2)$ & ref. & \\
\hline T allele & $102(38.6)$ & $196(40.8)$ & $0.912(0.671-1.241)$ & 0.558 \\
\hline Male $n$ & 51 & 67 & & \\
\hline $\mathrm{CC}$ & $21(41.2)$ & $17(25.4)$ & ref. & \\
\hline CT & $22(43.1)$ & $32(47.7)$ & $0.557(0.241-1.288)$ & 0.169 \\
\hline $\mathrm{TT}$ & $8(15.7)$ & $18(26.9)$ & $0.360(0.126-1.028)$ & 0.053 \\
\hline $\mathrm{CT} / \mathrm{TT}$ & $30(58.8)$ & $50(74.6)$ & $0.486(0.222-1.063)$ & 0.069 \\
\hline CC vs. CT/TT & & & $2.059(0.941-4.507)$ & 0.069 \\
\hline C allele & $64(62.7)$ & $66(49.3)$ & ref. & \\
\hline T allele & $38(37.3)$ & $68(50.7)$ & $0.576(0.341-0.974)$ & 0.039 \\
\hline \multicolumn{5}{|c|}{ TGFBR2 -875G/A（rs3087465) } \\
\hline Total N & 183 & 307 & & \\
\hline GG & $125(68.3)$ & $193(62.9)$ & ref. & \\
\hline GA & $49(26.8)$ & $102(33.2)$ & $0.742(0.493-1.116)$ & 0.151 \\
\hline AA & $9(4.9)$ & $12(3.9)$ & $1.158(0.474-2.829)$ & 0.747 \\
\hline G allele & $299(81.7)$ & $488(79.5)$ & ref. & \\
\hline A allele & $67(18.3)$ & $126(20.5)$ & $0.868(0.624-1.207)$ & 0.399 \\
\hline Female $n$ & 132 & 240 & & \\
\hline GG & $93(70.4)$ & $159(66.3)$ & ref. & \\
\hline GA & $34(25.8)$ & $72(30)$ & $0.807(0.449-1.307)$ & 0.383 \\
\hline AA & $5(3.8)$ & $9(3.7)$ & $0.950(0.309-2.919)$ & 0.928 \\
\hline G allele & $220(83.3)$ & $390(81.3)$ & ref. & \\
\hline A allele & 44 (16.7) & $90(18.7)$ & $0.867(0.583-1.289)$ & 0.479 \\
\hline Male $n$ & 51 & 67 & & \\
\hline GG & $32(62.8)$ & $34(50.7)$ & ref. & \\
\hline GA & $15(29.4)$ & $30(44.8)$ & $0.531(0.242-1.165)$ & 0.113 \\
\hline AA & $4(7.8)$ & $3(4.5)$ & $1.417(0.294-6.829)$ & 0.663 \\
\hline G allele & $79(77.5)$ & $98(73.1)$ & ref. & \\
\hline A allele & $23(22.5)$ & 36 (26.9) & $0.793(0.434-1.446)$ & 0.448 \\
\hline
\end{tabular}

RRMS - relapsing-remitting multiple sclerosis, OR - odds ratios, $\mathrm{Cl}$ - confidence intervals 
Table III. Combination of genotypes -509C/T TGFB1 and -875G/A TGFBR2 promoter polymorphisms

\begin{tabular}{|c|c|c|c|c|c|}
\hline TGFB1 -509C/T & $\begin{array}{l}\text { TGFBR2 } \\
-875 G / A\end{array}$ & $\begin{array}{l}\text { RRMS } \\
n(\%)\end{array}$ & $\begin{array}{c}\text { Controls } \\
n(\%)\end{array}$ & OR $(95 \% \mathrm{Cl})$ & $P$-value \\
\hline Total N & & 183 & 307 & & \\
\hline $\mathrm{CC}$ & GG & $47(25.7)$ & $70(22.8)$ & ref. & \\
\hline $\mathrm{CC}$ & GA & $19(10.4)$ & $29(9.5)$ & $0.976(0.491-1.939)$ & 0.944 \\
\hline CC & $A A$ & $4(2.2)$ & $5(1.6)$ & $1.191(0.304-4.669)$ & 0.801 \\
\hline $\mathrm{CC}$ & GA/AA & $23(12.6)$ & 34 (11.1) & $1.008(0.528-1.921)$ & 0.982 \\
\hline CT & GG & $59(32.2)$ & $91(29.6)$ & $0.966(0.589-1.582)$ & 0.890 \\
\hline CT & GA & $24(13.1)$ & $48(15.7)$ & $0.745(0.403-1.376)$ & 0.346 \\
\hline $\mathrm{CT}$ & AA & $3(1.6)$ & $3(1)$ & $1.489(0.288-7.697)$ & 0.633 \\
\hline $\mathrm{CT}$ & GA/AA & $27(14.7)$ & $51(16.6)$ & $0.788(0.435-1.430)$ & 0.434 \\
\hline TT & GG & $19(10.4)$ & $32(10.4)$ & $0.884(0.449-1.741)$ & 0.722 \\
\hline $\mathrm{TT}$ & GA & $6(3.3)$ & $25(8.1)$ & $0.357(0.136-0.938)$ & 0.032 \\
\hline TT & AA & $2(1.1)$ & $4(1.3)$ & $0.745(0.131-4.231)$ & 0.739 \\
\hline $\mathrm{TT}$ & $\mathrm{GA}+\mathrm{AA}$ & $8(4.4)$ & $29(9.4)$ & $0.411(0.173-0.976)$ & 0.040 \\
\hline $\mathrm{CT} / \mathrm{TT}$ & GG & $78(42.6)$ & $123(40)$ & $0.944(0.593-1.505)$ & 0.810 \\
\hline $\mathrm{CT} / \mathrm{TT}$ & GA & $30(16.4)$ & $73(23.8)$ & $0.612(0.348-1.075)$ & 0.087 \\
\hline $\mathrm{CT} / \mathrm{TT}$ & GA/AA & 35 (19.1) & $80(26.1)$ & $0.652(0.379-1.121)$ & 0.121 \\
\hline Female $n$ & 132 & 240 & & & \\
\hline $\mathrm{CC}$ & GG & $33(25)$ & $60(25)$ & ref. & \\
\hline CC & GA & $13(9.8)$ & $23(9.6)$ & $1.028(0.461-2.291)$ & 0.947 \\
\hline $\mathrm{CC}$ & AA & $3(2.3)$ & $4(1.7)$ & $1.364(0.288-6.464)$ & 0.695 \\
\hline CC & $G A+A A$ & $16(12.1)$ & $27(11.3)$ & $1.077(0.509-2.281)$ & 0.845 \\
\hline $\mathrm{CT}$ & GG & $47(35.6)$ & $76(31.7)$ & $1.124(0.643-1.967)$ & 0.681 \\
\hline CT & GA & $16(12.1)$ & 31 (12.9) & $0.938(0.449-1.963)$ & 0.866 \\
\hline $\mathrm{CT}$ & AA & $1(0.8)$ & $3(1.2)$ & $0.606(0.061-6.061)$ & 0.667 \\
\hline $\mathrm{CT}$ & $\mathrm{GA}+\mathrm{AA}$ & $17(12.9)$ & 34 (14.2) & $0.909(0.442-1.869)$ & 0.795 \\
\hline TT & GG & $13(9.8)$ & $23(9.6)$ & $1.028(0.461-2.291)$ & 0.947 \\
\hline TT & GA & $5(3.8)$ & $18(7.5)$ & $0.505(0.172-1.484)$ & 0.209 \\
\hline $\mathrm{TT}$ & AA & $1(0.8)$ & $2(0.8)$ & $0.909(0.079-10.407)$ & 0.939 \\
\hline $\mathrm{TT}$ & GA/AA & $6(4.5)$ & $20(8.3)$ & $0.545(0.199-1.492)$ & 0.233 \\
\hline Male $n$ & 51 & 67 & & & \\
\hline CC & GG & $14(27.4)$ & $10(14.9)$ & ref. & \\
\hline $\mathrm{CC}$ & GA & $6(11.7)$ & $6(9)$ & $0.714(0.177-2.875)$ & 0.729 \\
\hline CC & $A A$ & $1(2)$ & $1(1.5)$ & $0.714(0.040-12.829)$ & 0.819 \\
\hline $\mathrm{CC}$ & GA/AA & $7(13.7)$ & $7(10.4)$ & $0.714(0.190-2.688)$ & 0.618 \\
\hline $\mathrm{CT}$ & GG & $12(23.5)$ & $15(22.4)$ & $0.571(0.188-1.736)$ & 0.322 \\
\hline $\mathrm{CT}$ & GA & $8(15.7)$ & $17(25.4)$ & $0.336(0.105-1.081)$ & 0.064 \\
\hline $\mathrm{CT}$ & GA/AA & $10(19.6)$ & $17(25.4)$ & $0.420(0.136-1.296)$ & 0.128 \\
\hline $\mathrm{TT}$ & GG & $6(11.8)$ & $9(13.4)$ & $0.467(0.128-1.771)$ & 0.265 \\
\hline $\mathrm{TT}$ & GA & $1(2)$ & $7(10.4)$ & $0.102(0.011-0.965)$ & $0.066^{c}$ \\
\hline TT & AA & $1(2)$ & $2(3)$ & $0.357(0.028-4.501)$ & 0.411 \\
\hline $\mathrm{TT}$ & GA/AA & $2(4)$ & $9(13.4)$ & $0.159(0.028-0.899)$ & $0.065^{c}$ \\
\hline $\mathrm{CT} / \mathrm{TT}$ & GA/AA & $12(6.6)$ & $26(8.5)$ & $0.687(0.316-1.496)$ & 0.343 \\
\hline $\mathrm{CT} / \mathrm{TT}$ & $\mathrm{GA}$ & $9(17.6)$ & $24(35.8)$ & $0.268(0.088-0.818)$ & 0.018 \\
\hline
\end{tabular}

RRMS - relapsing-remitting multiple sclerosis, OR - odds ratios, $\mathrm{Cl}$-confidence intervals, $p^{c}-$ Yates' corrected $p$ value 
clinical manifestation of RRMS, we found differences between genotype distribution among patients with early (under 30 years) and late (above 30 years) onset of the disease. Moreover, we investigated the combined effects of both polymorphism variants with the risk of the onset of the disease (Table IV). The frequency of the combined TGFB1C[-509]C and TGFBR2G[-875]A genotype was overrepresented among patients with early onset of RRMS than patients with late onset $(15.8 \%$ vs. $4.6 \%, \mathrm{OR}=3.913,95 \% \mathrm{Cl}$ :
1.130-13.554, $p=0.05)$. Similarly, the patients with early onset showed a higher frequency of the combination variant of TGFB1C[-509]C and TGFBR2G[-875] A/TGFBR2A[-875]A than those with late onset of the disease $(19 \%$ vs. $5.7 \%, \mathrm{OR}=3.757,95 \% \mathrm{Cl}$ : 1.197 $11.793, p=0.019)$. Likewise, in women with an early onset of RRMS a higher frequency of combined effects of TGFB1C[-509]C and TGFBR2G[-875]A genotypes as well as TGFB1C[-509]C and TGFBR2G[-875]A/ TGFBR2A[-875]A genotypes were observed compared

Table IV. Association of -509C/T TGFB1 and -875G/A TGFBR2 polymorphisms with onset of relapsing-remitting multiple sclerosis (RRMS)

\begin{tabular}{|c|c|c|c|c|c|}
\hline $\begin{array}{l}\text { TGFB1 } \\
-509 \mathrm{C} / \mathrm{T}\end{array}$ & $\begin{array}{l}\text { TGFBR2 } \\
-875 \mathrm{G} / \mathrm{A}\end{array}$ & $\begin{array}{c}\text { Early onset } \\
n(\%)\end{array}$ & $\begin{array}{c}\text { Late onset } \\
n(\%)\end{array}$ & OR $(95 \% \mathrm{Cl})$ & $P$-value \\
\hline Total N & 95 & 88 & & & \\
\hline $\mathrm{CC}$ & GG & $23(24.2)$ & $24(27.3)$ & ref. & \\
\hline $\mathrm{CC}$ & GA & $15(15.8)$ & $4(4.6)$ & 3.913 (1.130-13.554) & $0.050^{c}$ \\
\hline $\mathrm{CC}$ & AA & $3(3.2)$ & $1(1.1)$ & $3.130(0.303-32.314)$ & 0.317 \\
\hline $\mathrm{CC}$ & GA/AA & $18(19)$ & $5(5.7)$ & 3.757 (1.197-11.793) & 0.019 \\
\hline $\mathrm{CT}$ & GG & $25(26.3)$ & $34(38.6)$ & $0.767(0.355-1.658)$ & 0.500 \\
\hline $\mathrm{CT}$ & GA & $15(15.8)$ & $9(10.2)$ & $1.739(0.637-4.751)$ & 0.278 \\
\hline $\mathrm{CT}$ & AA & $1(1)$ & $2(2.3)$ & $0.522(0.044-6.154)$ & 0.600 \\
\hline $\mathrm{CT}$ & GA/AA & $16(16.8)$ & $11(12.5)$ & $1.518(0.583-3.953)$ & 0.392 \\
\hline $\mathrm{TT}$ & GG & $9(9.5)$ & $10(11.4)$ & $0.939(0.323-2.729)$ & 0.908 \\
\hline $\mathrm{TT}$ & GA & $3(3.2)$ & $3(3.4)$ & $1.043(0.191-5.709)$ & 0.961 \\
\hline $\mathrm{TT}$ & AA & $1(1)$ & $1(1.1)$ & $1.043(0.062-17.686)$ & 0.976 \\
\hline $\mathrm{TT}$ & GA/AA & $4(4.2)$ & $4(4.5)$ & $1.043(0.233-4.673)$ & 0.956 \\
\hline $\mathrm{CT} / \mathrm{TT}$ & GG & $34(35.8)$ & $44(50)$ & $0.806(0.390-1.667)$ & 0.561 \\
\hline $\mathrm{CT} / \mathrm{TT}$ & GA/AA & $20(21)$ & $15(17)$ & $1.391(0.577-3.356)$ & 0.462 \\
\hline $\mathrm{CC} / \mathrm{TT}$ & GA/AA & $22(23.2)$ & $9(10.2)$ & $2.551(0.973-6.686)$ & 0.054 \\
\hline Female $n$ & 62 & 70 & & & \\
\hline CC & GG & $11(17.8)$ & $19(27.1)$ & ref. & \\
\hline $\mathrm{CC}$ & GA & $11(17.8)$ & $5(7.1)$ & $3.800(1.044-13.830)$ & 0.038 \\
\hline $\mathrm{CC}$ & $\mathrm{AA}$ & $2(3.2)$ & $1(1.4)$ & $3.455(0.280-42.622)$ & 0.311 \\
\hline $\mathrm{CC}$ & AG/AA & $13(21)$ & $6(8.6)$ & $3.742(1.105-12.670)$ & 0.030 \\
\hline $\mathrm{CT}$ & GG & 19 (30.6) & 27 (38.6) & $1.215(0.472-3.132)$ & 0.686 \\
\hline $\mathrm{CT}$ & GA & $8(12.9)$ & $9(12.8)$ & $1.535(0.459-5.137)$ & 0.485 \\
\hline $\mathrm{CT}$ & GA/AA & $9(14.5)$ & $9(12.8)$ & $1.727(0.528-5.651)$ & 0.364 \\
\hline TT & GG & $6(9.7)$ & $5(7.1)$ & $2.073(0.511-8.405)$ & 0.303 \\
\hline $\mathrm{TT}$ & GA & $2(3.2)$ & $4(5.7)$ & $0.864(0.135-5.507)$ & 0.877 \\
\hline $\mathrm{TT}$ & GA/AA & $4(6.5)$ & $4(5.7)$ & $1.727(0.359-8.322)$ & 0.493 \\
\hline Male $n$ & 33 & 18 & & & \\
\hline $\mathrm{CC}$ & GG & $8(24.2)$ & $4(22.2)$ & ref. & \\
\hline CT & GG & $7(21.2)$ & $6(33.3)$ & $0.583(0.115-2.952)$ & 0.513 \\
\hline $\mathrm{CT}$ & GA & $5(15.2)$ & $3(16.7)$ & $0.833(0.129-5.396)$ & 0.848 \\
\hline $\mathrm{CT}$ & GA/AA & $6(18.2)$ & $3(16.7)$ & $1.000(0.160-6.255)$ & 1.000 \\
\hline TT & GG & $3(9.1)$ & $4(22.2)$ & $0.375(0.055-2.555)$ & 0.311 \\
\hline
\end{tabular}

OR - odds ratios, $\mathrm{Cl}$ - confidence intervals, $p^{c}-$ Yates' corrected $p$ value 
with the women with the late onset $(17.8 \%$ vs. $7.1 \%$, $\mathrm{OR}=3.800,95 \% \mathrm{Cl}: 1.044-13.830, p=0.038 ; 21 \%$ vs. $8.6 \%, \mathrm{OR}=3.742,95 \% \mathrm{Cl}: 1.105-12.670, p=0.030)$ (Table IV). Analyses in the group of men showed no significant association in the combination of genotypes with the age of onset.

\section{Discussion}

In this study, we examined the genetic association between the two promoter polymorphisms in genes encoded the regulatory TGF- $\beta 1$ cytokine and its receptor and RRMS. The association between TGFB1T[-509]T genotype and TGFB1[-509] ${ }^{*}$ T allele was observed among males with RRMS, while the TGFBR2G[-875]A polymorphism was not associated with RRMS. Moreover, when the patient's genotype contains at least one TGFB1[-509] ${ }^{*}$ T allele (carriers of both TGFB1C[-509]T and TGFB1T[-509]T genotypes) in combination with TGFBR2G[-875]A genotype, the genetic risk for RRMS was decreased approximately four-fold for men, compared to men carrying both wild-type homozygous TGFB1C[-509]C and TGFBR2G[-875]G genotypes (OR $=0.268, p=0.018)$.

The two investigated single-nucleotide polymorphisms (SNPS) are located at the promoter region of TGFB1 and TGFBR2 genes, which encodes proteins involved in the TGF- $\beta 1$ signalling pathway. A lot of studies with the use of animal models have already revealed a crucial role for TGF- $\beta 1$ in differentiation and pathogenicity of autoreactive Th1 cells in MS development $[4,16,19]$. The immunosuppressive and tolerogenic role of TGF- $\beta 1$ points to its gene as a potent candidate for a genetic predisposition to multiple sclerosis. Unfortunately, the first linkage analysis of the two polymorphic markers (D19S223 and D19S224) located close to the TGFB1 gene with MS has not yielded positive results [9]. McDonnell et al. demonstrated no association between two TGF- $\beta 1$ gene microsatellite markers and MS susceptibility among patients with relapsing-remitting and secondary progressive MS from Northern Ireland [20]. Green et al. investigated TGFB1 haplotypes, consisting of five closely linked single nucleotide polymorphisms within the TGFB1 locus: two occurring in the promoter region G[-800]A, C[-509]T, two in exon 1 (Leu10Pro)/ rs1982073, (Arg25Pro)/rs1800471, and one in exon 5 (Thr263lle)/rs1800474, by linkage analysis, and reported no significant association with MS. However, testing of individual TGFB1 gene polymorphisms revealed significant associations between patients with "mild"
MS (EDSS < 3) and wild-type genotypes of both TGF$B 1 C[-509] T$ and Leu10Pro SNPs. The authors concluded that the TGFB1 gene variability influences disease expression rather than disease susceptibility [6]. Similar results were observed by Weinshenker et al. [35]. Among MS patients, the TGFB1[-509]*C allele was associated with higher disease severity. Those studies did not provide clear answers about the role of TGFB1 gene polymorphisms in MS development. Moreover, several polymorphisms in the TGFB1 gene affecting TGF- $\beta 1$ production have been identified $[5,18]$.

In general, our results for the association between the promoter TGFB1C[-509]T polymorphism and RRMS susceptibility are in line with all the studies cited above. However, when we stratified the patients' group by gender a significant difference was observed between the males with TGFB1T[-509]T genotype in cases and controls. Our results demonstrated that TGFB1[-509] ${ }^{\star} T$ allele and TGFB1T[-509]T genotype may protect against RRMS in men. Similar results for the gender dependency have been published for two TGFB1 gene SNPs located in the first exon at +869 position (Leu10Pro) and +915 position (Arg25Pro) associated with MS in Dutch Caucasian patients. The authors concluded that TGFB1T[+869]C (Leu10Pro) (rs1982073) gene polymorphism is associated with MS susceptibility, especially in males [27]. The sex-dependent differences in gene expression, particularly for the TGFB1 gene, could explain these results. In our recent study, we demonstrated that TGF- $\beta 1$ serum levels depend on the TGFB1C[-509]T genotype in combination with gender and age. The highest levels of the cytokine occur in males with homozygous TGFB1T[-509]T genotype [33]. Taking into account that men with TT genotype produced higher quantities of TGF- $\beta 1$ in serum, this genotype could be a possible protective factor for MS development. This is in line with the observation of the neuroprotective effects of TGF- $\beta 1$ [3].

Recently, the role that TGF- $\beta 1$ plays in the generation and regulation of encephalitogenic $T$ cells and the function of CD4 regulatory $T$ cells in multiple sclerosis has been elucidated $[16,17]$. The inability of Tregs in patients with MS to suppress autoimmunity could be attributed to decreased TGFBR2 expression on the T-cell surface. This effect can be mediated by promoter polymorphism causing a G-to-A transition at position -875 in the TGFBR2 gene. Moreover, Seijo et al. reported that the presence of polymorphic TGF- 
$B R 2[-875]^{*} A$ in the promoter region enhanced the transcription activity of TGFBR2 in normal epithelial cells [28]. We did not find a significant association between genotypes of this polymorphism and MS susceptibility, although the patients with heterozygous genotype showed a trend towards diminished frequency in the RRMS group. The most significant association was observed when the genotypes of the two polymorphisms were combined. Obviously, the combination of TGFB1T[-509]T/TGFBR2G[-875]A genotypes has the most protective effect. In our studied group of RRMS patients, male carriers of the two genotypes displayed four-fold lower susceptibility than non-carriers $(\mathrm{OR}=0.268, p=0.018)$. At the same time, the combination of the TGFB1C[-509]C genotype with TGFBR2G[-875]A/TGFBR2A[-875] A was a much more susceptible genotype for early onset of the disease $(\mathrm{OR}=3.757, p=0.019)$. The results clearly suggest the significance of both polymorphisms for MS susceptibility. Thus, our findings confirm previous results from many other studies on the role of the TGF- $\beta 1$ signalling pathway in the development of this autoimmune disease mediated by differentiation of T-cells. Recently, new evidence for the impact of miRNA on the TGF- $\beta$ signalling pathway and its dysregulation in multiple sclerosis has been found [29].

Nowadays, there is a consensus that the enhancement of TGF- $\beta 1$ signalling could positively modulate Tregs cell differentiation and diminishes the activities of encephalopathic Th-17 cells in MS patients. Moreover, TGF- $\beta 1$ can directly enhance IL-10 production, which negatively regulates the function of effector myelin-specific Th1 cells in MS patients [11].

We should mention some limitations of our study. The patient group consisted only of subjects with RRMS. Patients with PPMS or SPMS were not included. The number of male patients with RRMS was relatively small; therefore, our results are preliminary and need confirmation with the use of a larger cohort of patients. MS is a complex disease; thus, other genetic and environmental factors certainly also affect disease development.

In summary, for the first time, we demonstrate a link between the TGFB1C[-509]T genotype and MS. Male carriers of at least one TGFB1[-509] ${ }^{\star} T$ allele have a lower genetic risk of MS development, which is additionally reduced when the genotype coexists with the TGFBR2[-875] ${ }^{*}$ A allele. This combined genotype played a protective role for all patients in our group, while the combined genotype including TGFB1C[-509]C genotype instead of TGFB1T[-509]T seems to predispose to early onset of MS development.

\section{Acknowledgments}

This work was supported by Trakia University, Medical Faculty, Stara Zagora, Bulgaria under research grant No. 1/2017.

\section{Disclosure}

The authors report no conflict of interest.

\section{References}

1. Compston A, Coles A. Multiple sclerosis. Lancet 2008; 372: 1502-1517.

2. Dendrou CA, Fugger L, Friese MA. Immunopathology of multiple sclerosis. Nat Rev Immunol 2015; 15: 545-558.

3. Dobolyi A, Vincze C, Pál G, Lovas G. The neuroprotective functions of transforming growth factor beta proteins. Int J Mol Sci 2012; 13: 8219-8258.

4. Gorelik L, Flavell RA. Abrogation of TGFbeta signaling in T cells leads to spontaneous $T$ cell differentiation and autoimmune disease. Immunity 2000; 12: 171-181.

5. Grainger DJ, Heathcote K, Chiano M, Snieder H, Kemp PR, Metcalfe JC, Carter ND, Spector TD. Genetic control of the circulating concentration of transforming growth factor type beta1. Hum Mol Genet 1999; 8: 93-97.

6. Green AJ, Barcellos LF, Rimmler JB, Garcia ME, Caillier S, Lincoln RR, Bucher P, Pericakvance MA, Haines MA, Hauser SL, Oksenberg JR. Sequence variation in the transforming growth factor-beta1 (TGFB1) gene and multiple sclerosis susceptibility. J Neuroimmunol 2001; 116: 116-124.

7. Haas J, Fritzsching B, Trübswetter P, Korporal M, Milkova L, Fritz B, Vobis D, Krammer PH, Suri-Payer E, Wildemann B. Prevalence of newly generated naive regulatory T cells (Treg) is critical for Treg suppressive function and determines Treg dysfunction in multiple sclerosis. J Immunol 2007; 179: 1322-1330.

8. Haas J, Hug A, Viehöver A, Fritzsching B, Falk CS, Filser A, Vetter T, Milkova L, Korporal M, Fritz B, Storch Hagenlocher B. Reduced suppressive effect of CD4+CD25 high regulatory $T$ cells on the $T$ cell immune response against myelin oligodendrocyte glycoprotein in patients with multiple sclerosis. Eur J Immunol 2005; 35: 3343-3352.

9. He B, Xu C, Yang B, Landtblom AM, Fredrikson S, Hillert J. Linkage and association analysis of genes encoding cytokines and myelin proteins in multiple sclerosis. J Neuroimmunol 1998; 86: 13-19.

10. Huss DJ, Winger RC, Peng H, Yang Y, Racke MK, Lovett-Racke AE. TGF-beta enhances effector Th1 cell activation but promotes self-regulation via IL-10. J Immunol 2010; 184: 5628-5636.

11. Huss DJ, Winger RC, Cox GM, Guerau-de-Arellano M, Yang Y, Racke MK, Lovett-Racke AE. TGF- signaling via Smad4 drives 
IL-10 production in effector Th1 cells and reduces T-cell trafficking in EAE. Eur J Immunol 2011; 41: 2987-2996.

12. Iglesias A, Bauer J, Litzenburger T, Schubart A, Linington C. $\mathrm{T}$ - and B-cell responses to myelin oligodendrocyte glycoprotein in experimental autoimmune encephalomyelitis and multiple sclerosis. Glia 2001; 36: 220-234.

13. Jin G, Wang L, Chen W, Hu Z, Zhou Y, Tan Y, Wang J, Hua Z, Ding W, Shen J, Zhang Z. Variant alleles of TGFB1 and TGFBR2 are associated with a decreased risk of gastric cancer in a Chinese population. Int J Cancer 2007; 120: 1330-1335.

14. Kumar M, Putzki N, Limmroth V, Remus R, Lindemann M, Knop D, Mueller N, Hardt C, Kreuzfelder E, Grosse-Wilde H. CD4+CD25+FoxP3+ T lymphocytes fail to suppress myelin basic protein-induced proliferation in patients withmultiple sclerosis. J Neuroimmunol 2006; 180: 178-184.

15. Kurtzke JF. Rating neurologic impairment in multiple sclerosis: an expanded disability status scale (EDSS). Neurology 1983; 33 : 1444-1452.

16. Lee PW, Yang Y, Racke MK, Lovett-Racke AE. Analysis of TGF- $\beta 1$ and TGF- $\beta 3$ as regulators of encephalitogenic Th17 cells: Implications for multiple sclerosis. Brain Behav Immun 2015; 46: 44-49.

17. Lee PW, Severin ME, Lovett-Racke AE. TGF- $\beta$ regulation of encephalitogenic and regulatory $T$ cells in multiple sclerosis. Eur I Immunol 2017; 47: 446-453.

18. Li H, Romieu I, Wu H, Sienra-Monge JJ, Ramírez-Aguilar M, del Río-Navarro BE, del Lara-Sánchez IC, Kistner EO, Gjessing HK, London SJ. Genetic polymorphisms in transforming growth factor beta-1 (TGFB1) and childhood asthma and atopy. Hum Genet 2007; 121: 529-538.

19. Liu Y, Zhang P, Li J, Kulkarni AB, Perruche S, Chen W. A critical function for TGF-beta signaling in the development of natural CD4+CD25+Foxp3+ regulatory T cells. Nat Immunol 2008; 9: 632-640.

20. McDonnell GV, Kirk CW, Hawkins SA, Graham CA. Lack of association of transforming growth factor (TGF)- $\beta 1$ and $\beta 2$ gene polymorphisms with multiple sclerosis (MS) in Northern Ireland. Mult Scler 1999; 5: 105-109.

21. McGeachy MJ, Stephens LA, Anderton SM. Natural recovery and protection from autoimmune encephalomyelitis: contribution of CD4+CD25+ regulatory cells within the central nervous system. J Immunol 2005; 175: 3025-3032.

22. Meira M, Sievers C, Hoffmann F, Rasenack M, Kuhle J, Derfuss T, Kappos L, Lindberg RLP. Unraveling natalizumab effects on deregulated miR-17 expression in CD4+ T cells of patients with relapsing-remitting multiple sclerosis. J Immunol 2014; 2014: 897249.

23. Meoli EM, Oh U, Grant CW, Jacobson S. TGF- $\beta$ signaling is altered in the peripheral blood of subjects with multiple sclerosis. J Neuroimmunol 2011; 230: 164-168.

24. Mirshafiey A, Mohsenzadegan M. TGF-b as a promising option in the treatment of multiple sclerosis. Neuropharmacology 2009; 56: 929-936.

25. Monteleone I, Pallone F, Monteleone G. Th17-related cytokines: new players in the control of chronic intestinal inflammation. BMC Med 2011; 9: 122-132.
26. Polman CH, Reingold SC, Banwell B, Clanet M, Cohen JA, Filippi M, Fujihara K, Havrdova E, Hutchinson M, Kappos L, Lublin FD. Diagnostic criteria for multiple sclerosis: 2010 revisions to the McDonald criteria. Ann Neurol 2011; 69: 292-302.

27. Schrijver HM, Crusius JB, García-González MA, Polman CH, Peña AS, Barkhof F, Uitdehaag BM. Gender-related association between the TGFB1+869 polymorphism and multiple sclerosis. J Interferon Cytokine Res 2004; 24: 536-542.

28. Seijo ER, Song H, Lynch MA, Jennings R, Qong X, Lazaridis E, Muro-Cacho C, Weghorst CM, Muñoz-Antonia T. Identification of genetic alterations in the TGF $\beta$ type II receptor gene promoter. Mutat Res 2001; 483: 19-26.

29. Severin ME, Lee PW, Liu Y, Selhorst AJ, Gormley MG, Pei W, Yang Y, Guerau-de-Arellano M, Racke MK, Lovett-Racke AE. MicroRNAs targeting TGF $\beta$ signaling underlie the regulatory $T$ cell defect in multiple sclerosis. Brain 2016; 139: 1747-1761.

30. Shah R, Hurley CK, Posch PE. A molecular mechanism for the differential regulation of TGF-beta1 expression due to the common SNP -509C-T (c-1347C > T). Hum Genet 2006; 120: 461469.

31. Shi Y, Massague J. Mechanisms of TGF- $\beta$ signaling from cell membrane to the nucleus. Cell 2003; 113: 685-700.

32. Shull MM, Ormsby I, Kier AB, Pawlowski S, Diebold RJ, Yin M, Allen R, Sidman C, Proetzel G, Calvin D, Annunziata N. Targeted disruption of the mouse transforming growth factor- $\beta 1$ gene results in multifocal inflammatory disease. Nature 1992; 359: 693-699.

33. Stanilova S, Stanilov N, Julianov A, Manolova I, Miteva L. Transforming growth factor- $\beta 1$ gene promoter -509C/T polymorphism in association with expression affects colorectal cancer development and depends on gender. PLoS One 2018; 13: e0201775.

34. Viglietta V, Baecher-Allan C, Weiner HL, Hafler DA. Loss of functional suppression by CD4+CD25+ regulatory T cells in patients with multiple sclerosis. J Exp Med 2004; 199: 971-979.

35. Weinshenker BG, Hebrink D, Kantarci OH, Schaefer-Klein J, Atkinson E, Schaid D, McMurray CM. Genetic variation in the transforming growth factor betal gene in multiple sclerosis. J Neuroimmunol 2001; 120: 139-145.

36. Yang Y, Weiner J, Liu Y, Smith AJ, Huss DJ, Winger R, Peng H, Cravens PD, Racke MK, Lovett-Racke AE. T-bet is essential for encephalitogenicity of both Th1 and Th17 cells. J Exp Med 2009; 206: 1549-1564. 